\title{
Primary renal pelvis and ureter squamous cell carcinoma (SCC): a rare case report and review of literature
}

This article was published in the following Dove Press journal: International Medical Case Reports Journal

\author{
Mehdi Salehipour' \\ Niloofar Dastgheib ${ }^{2}$ \\ Masood Hosseinzadeh ${ }^{3}$ \\ Alireza Makarem' \\ Alireza Rezvani ${ }^{4}$ \\ Alireza Sanati ${ }^{1}$ \\ Sona Tayebi ${ }^{\prime}$
}

'Department of Urology, Shiraz University of Medical Sciences, Shiraz, Iran; ${ }^{2}$ Student Research Committee, Shiraz University of Medical Sciences, Shiraz, Iran; ${ }^{3}$ Department of Pathology, Shiraz University of Medical Sciences, Shiraz, Iran; ${ }^{4}$ Department of Hematology, Shiraz University of Medical Sciences, Shiraz, Iran
Correspondence: Alireza Makarem Department of Urology, Shiraz University of Medical Science, P.O.Box: 7 I88858856 Shiraz, Iran

Tel +987132326645

$\mathrm{Fax}+987132331006$

Email alirezamakarem200I@gmail.com

\begin{abstract}
Primary renal squamous cell carcinoma (SCC) is a very rare upper urinary tract neoplasm. Renal SCC has a poor prognosis because it usually presents in advanced stages. We report a 64-year-old woman with a right paravertebral mass; after right radical nephroureterectomy and salpingo-oophorectomy, pathologic examination revealed primary SCC.
\end{abstract}

Keywords: SCC, neoplasm, kidney

\section{Introduction}

Primary renal squamous cell carcinoma (SCC) is extremely rare and accounts for less than $1 \%$ of all malignant renal tumors. ${ }^{1}$ Renal SCC has a poor prognosis because it usually presents in advanced stages. ${ }^{2}$ In most cases, renal SCC is associated with chronic infections, chronic renal calculi, radiotherapy or any factor that can irritate the urothelium. ${ }^{3,4}$

Herein, we report a case of primary renal SCC in a middle age woman. To the best of our knowledge, only few cases of primary renal SCC have been published in English literature so far.

\section{Case report}

A 65-year-old woman presented with nausea, vomiting, anorexia, and right hypogastric pain radiated to her right flank. The patient's history showed negative results for renal colic, chronic infections, previous radiotherapy, analgesic abuse and hematuria, or pyuria. On physical examination, the patient suffered from right flank tenderness. The laboratory findings were as follows:

Hemoglobin: $10.3 \mathrm{~g} / \mathrm{dL}$; White blood cell: $10.6 \times 10^{3} / \mathrm{mm}^{3}$; Platelet: $370 \times 10^{3} /$ $\mathrm{mm}^{3}$; International normalized ratio:1; Blood urea nitrogen: $15 \mathrm{mg} / \mathrm{dL}$; Creatinine: $1.4 \mathrm{mg} / \mathrm{dL}$; Na: $137 \mathrm{mmol} / \mathrm{L}$; K: $4.3 \mathrm{mmol} / \mathrm{L}$; calcium: $8.9 \mathrm{mEq} / \mathrm{dL}$; serum Phosphorus: $4 \mathrm{mg} / \mathrm{dL}$; LDH: $154 \mathrm{Iu} / \mathrm{L}$; and Ferritin: $25.7 \mathrm{ng} / \mathrm{mL}$. Liver function tests were normal. Chest X-ray was normal as well. Urinalysis showed microhematuria, and urine cytopathology showed no malignancy.

Ultrasonography and abdominopelvic CT scan revealed no dilatation of the pelvicalyceal system, there was a significant dilatation of the right renal pelvis, measuring approximately $3 \mathrm{~cm}$. The right upper and mid-ureter was also dilated, measuring approximately $8 \mathrm{~mm}$. This was not seen in the right ureter. Magnetic Resonance Urography revealed right-sided moderate to severe hydronephrosis and 
moderate hydroureter to mid-ureter, secondary to an extrinsic paravertebral soft tissue mass (measuring approximately $2 \times 2.7 \times 3.8 \mathrm{~cm}$ ), encasing the ureter at the level of the right iliac vessels bifurcation. (Figure 1) Color Doppler ultrasonography of the lower extremity veins was normal with no sign of DVT.

Biopsy from the mass was done under the guide of sonography by a radiologist, and immunohistochemistry results (especially CK20: Negative, CK7: Positive) were in favor of "poorly differentiated SCC with upper urinary tract origin". IHC results included CK20: Negative; CK7: Positive; P40: Positive; P16: Negative; CK5/6: Positive; and P63: Positive

There were no abnormal findings in the urinary bladder. Cystoscopy and the examination performed by gynecologists revealed that the genital system was not involved by the tumor.

The patient underwent right radical nephroureterectomy and salpinooophorectomy through midline abdominal incision, with the preoperative diagnosis of right midureteral SCC.

\section{Pathologic examination}

The right nephrectomy specimen was sent for pathology examination. The kidney and the attached ureter were $12 \dot{\times} 6 \dot{\times} 5 \mathrm{~cm}$. Multiple sections which were cut perpendicular to the hilum showed an infiltrative mass in the renal pelvis extending to the proximal ureter and renal parenchyma. The renal capsule and perinephric fat were free of

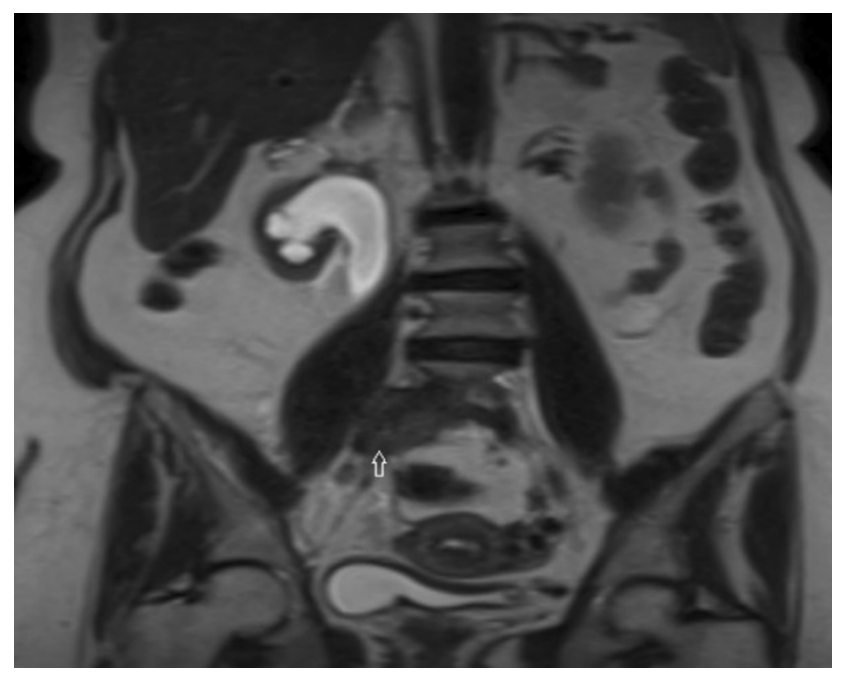

Figure I MR Urography revealed right-sided moderate to severe hydronephrosis and moderate hydroureter to mid ureter, secondary to an extrinsic paravertebral soft tissue mass (arrow) (measuring approximately $2 \times 2.7 \times 3.8 \mathrm{~cm}$ ), encasing the ureter at the level of the right iliac vessels bifurcation. tumor. The adnexa (ovary) was involved by poorly differentiated SCC, and Fallopian tube was free of tumor. Multiple microscopic sections $(1-5 \mu \mathrm{m})$ were prepared and stained with Hematoxyline and Eosine. Microscopic examination revealed invasive carcinoma with perivascular invasion (Figure 2)

Nests of malignant squamous cells infiltrated the periglomerular as well as the interstitial spaces (Figure 3). There were some neoplastic cells with small foci of keratin formation (Figure 4). There were also some Squamous nests with obvious intercellular desmosomes and bridges, which were characteristic for SCC (Figure 5).

Thus, the pathological stage was PT4 NxM1. The surgical margins were involved by the tumor.

With the above findings, diagnosis of the upper tract SCC was confirmed. The patient received four cycle chemotherapy (Gemcitabine+Cicplatine) as adjuvant therapy. Now after 6 months of follow-up, the patient is well with no evidence of recurrence of the tumor on the PET/CT study, urinary cytology, and cystoscopy.

\section{Discussion}

Primary renal SCC accounts for less than $1 \%$ of renal malignancies, so it is an extremely rare tumor. ${ }^{1}$ In a study conducted by by Perez-Montiel et al, only one out of 108 cases with SCC and renal pelvis high-grade urothelial carcinoma was noted. ${ }^{5}$ Only $0.7-8 \%$ of renal malignancies were SCC, and urothelial carcinoma was observed in more than $90 \%$ of renal pelvis tumors. The histologic hallmarks of SCC were intercellular bridges, pearl formation, and keratotic cellular debris. ${ }^{6}$ Renal SCC has a poor

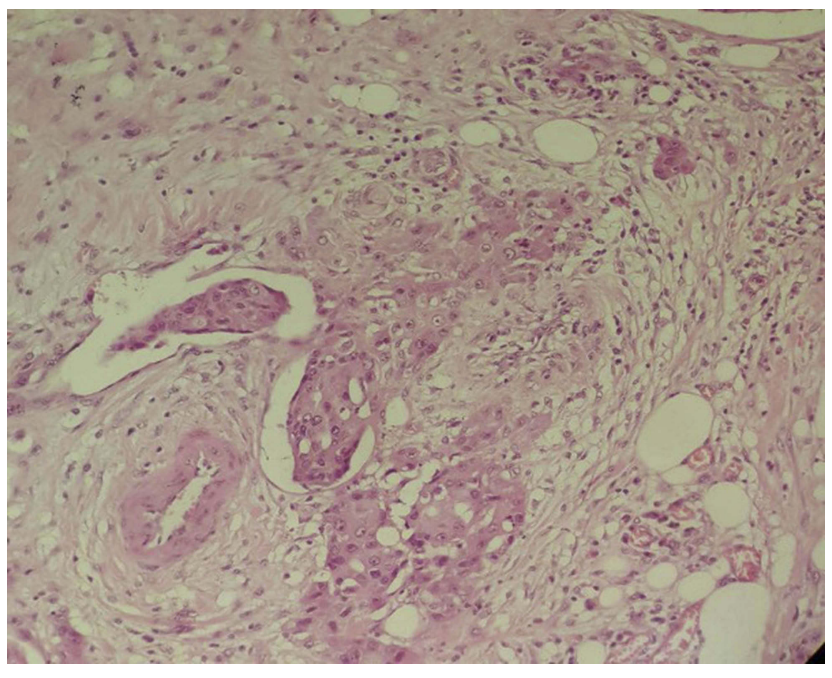

Figure 2 Invasive carcinoma with perivascular invasion. H\&E, I00X. 


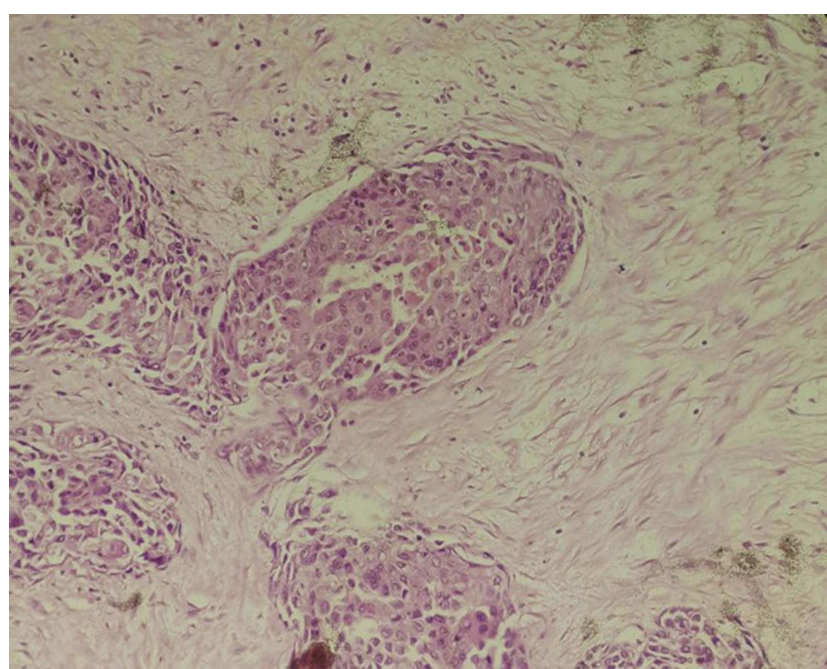

Figure 3 Nests of infiltrating carcinoma show squamoid differentiation. H\&E, I00X.

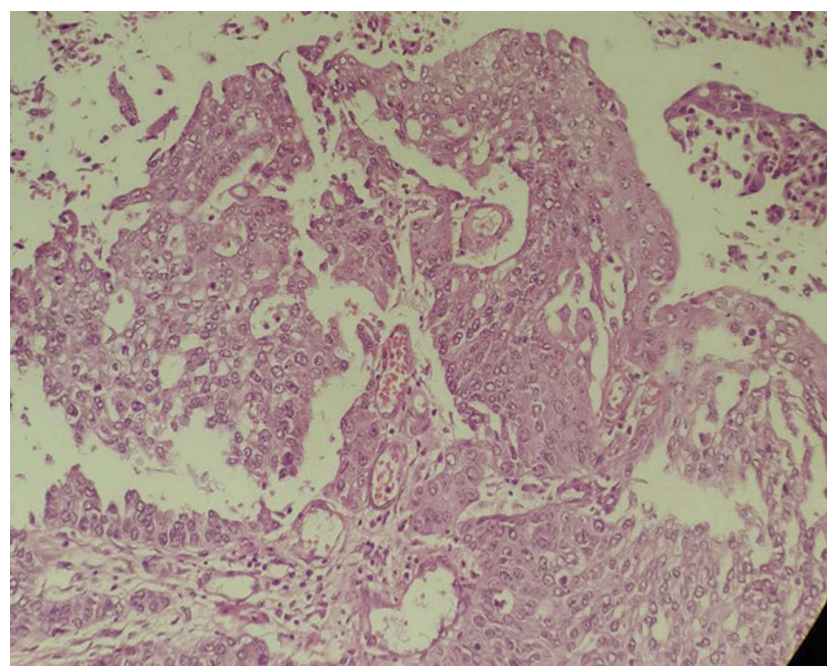

Figure 4 Neoplastic cells with small foci of keratin formation. H\&E, 400X.

prognosis because it presents in high grades, while being metastatic or locally advanced. Holmang et al, report that the probability of 5 -year survival is under $10 \%$, and the average post-operative survival rate is up to 7 months. ${ }^{7}$ In most patients, renal SCC was present at the age of 50-70 years. ${ }^{8}$ Chronic urothelium irritation caused by chronic infection, chronic renal calculi, radiotherapy, vitamin A deficiency, and analgesic abuse can lead to squamous metaplasia and then progress into SCC, but none of the mentioned factors was observed in our case. ${ }^{3}$

Hipparagi et al, reported a case of renal pelvis SCC with previous history of chronic pyelonephritis and renal calculi. ${ }^{8}$ Nachiappan et al, presented a 60 -year-old woman with Renal Pelvis SCC and history of pelvi-caliceal system

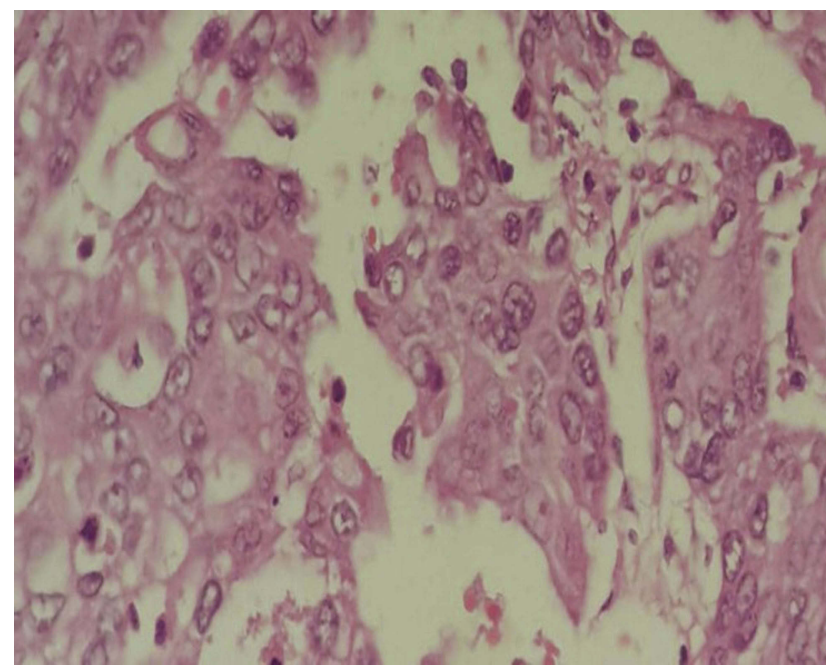

Figure 5 Squamous nests with intercellular desmosomes and bridges. H\&E, 400X.

calculi, severe hydronephrosis, and pyonephrosis. ${ }^{2}$ Renal SCC often presents with non-specific symptoms such as hematuria and abdominal pain. Imaging can show hydronephrosis, stone, and solid mass, but these findings are not specific for renal SCC. Therefore, histopathological studies are required for diagnosis. ${ }^{7}$ SCCs contain a keratinized area, so urine cytology can help the physician diagnose the disorder through detection of keratotic cellular debris, which was negative in our case. ${ }^{9}$ Compared to previous case reports in which only renal pelvis involvement by SCC was reported, in our case, the whole kidney parenchyma was involved by the tumor.

Given the limited number of reported cases with diagnosis of upper urinary tract SCC, there is little information about the best treatment for metastatic cases.

The primary treatment of these poorly differentiated tumors is surgery, even in metastatic lesions. ${ }^{10}$ Adjuvant or neoadjuvant chemotherapy with a combination of cisplatin, methotrexate, and bleomycin has minimal effect on treatment and they are more commonly used in metastatic cases. ${ }^{7}$

\section{Conclusion}

Upper tract SCC is a very rare uncommon tumor. Radiologic findings are non-specific, so the diagnosis of tumor occurs with delay and in advanced stages. The main treatment of SCC of the upper tract is surgical resection, and chemoradiotherapy is used as adjuvant therapy. Our case was rare with none of the risk factors of SCC. The patients with tumor risk factors should be recognized and regular workup should be done in order to diagnose the tumor in its early stage. 


\section{Ethics statement}

We declare that our study was approved by the ethics committee of Shiraz University of Medical Sciences, Shiraz, Iran. Additionally, written informed consent was obtained and the patient permitted us to publish the case details and any related images, the safety of our procedure, and its probable complications.

\section{Acknowledgments}

The authors would like to thank Nasrin Shokrpour from English Department for his editorial assistance in the Research Consulting Center (RCC) of Shiraz University of Medical Sciences for improving the use of English in the manuscript. No financial support for publication of this article has been received by the authors.

\section{Author contributions}

All authors contributed to data analysis, drafting or revising the article, gave final approval of the final version to be published, and agreed to be accountable for all aspects of the work.

\section{Disclosure}

The authors report no conflicts of interest in this work.

\section{References}

1. Li M, Cheung W. Squamous cell carcinoma of the renal pelvis. $J$ Urol. 1987;138(2):269-271.

2. Nachiappan M, Litake MM, Paravatraj VG, Sharma N, Narasimhan A. Squamous cell carcinoma of the renal pelvis, a rare site for a commonly known malignancy. J Clin Diagn Res. 2016;10(1):PD04.

3. Palmer CJ, Atty C, Sekosan M, Hollowell CMP, Wille MA. Squamous cell carcinoma of the renal pelvis. Urology. 2014;84 (1):8-11. doi:10.1016/j.urology.2013.11.020

4. Paonessa J, Beck H, Cook S. Squamous cell carcinoma of the renal pelvis associated with kidney stones: a case report. Med Oncol. 2011;28(1):392-394. doi:10.1007/s12032-010-9704-Z

5. Perez-Montiel D, Wakely PE Jr, Hes O, Michal M, Suster S. Highgrade urothelial carcinoma of the renal pelvis: clinicopathologic study of 108 cases with emphasis on unusual morphologic variants. Mod Pathol. 2006;19(4):494. doi:10.1038/modpathol.3800559

6. Mills SE, Carter D, Greenson JK, Reuter VE, Stoler MH. Sternberg's Diagnostic Surgical Pathology. Philadelphia, PA: Lippincott Williams \& Wilkins; 2012.

7. Holmäng S, Lele SM, Johansson SL. Squamous cell carcinoma of the renal pelvis and ureter: incidence, symptoms, treatment and outcome. J Urol. 2007;178(1):51-56. doi:10.1016/j.juro.2007.03.033

8. Hippargi SB, Nerune SM, Kumar M. Urothelial and squamous cell carcinoma of renal pelvis - a rare case report. J Clin Diagn Res. 2016;10(9):ED19.

9. Bernardini S, Adessi G-L, Billerey C, Chezy E, Carbillet J-P, Bittard $\mathrm{H}$. Immunohistochemical detection of $\mathrm{p} 53$ protein overexpression versus gene sequencing in urinary bladder carcinomas. $J$ Urol. 1999;162(4):1496-1501.

10. Mathur S, Rana P, Singh S, Goyal V, Sangwan M. Incidentally detected squamous cell carcinoma in non-functioning kidney presenting as multi-cystic mass. J Surg Case Rep. 2011;2011(9):8. doi:10.1093/jscr/2011.9.8

\section{Publish your work in this journal}

The International Medical Case Reports Journal is an international, peer-reviewed open-access journal publishing original case reports from all medical specialties. Previously unpublished medical posters are also accepted relating to any area of clinical or preclinical science. Submissions should not normally exceed 2,000 words or 4 published pages including figures, diagrams and references. The manuscript management system is completely online and includes a very quick and fair peer-review system, which is all easy to use. Visit http://www.dovepress.com/testimonials.php to read real quotes from published authors. 